\title{
DEL DAÑO MORAL AL DAÑO EXTRAPATRIMONIAL: LA SUPERACIÓN DEL PRETIUM DOLORIS
}

\author{
Dr. EU. MARCELO BARrientos Zamorano (M.D.E.) ${ }^{*}$
}

\begin{abstract}
RESUMEN: Considerando la lesión de un interés jurídicamente relevante se puede llegar a la compensación del daño no patrimonial y no solo por el dolor o sufrimiento que se padece. La visión reduccionista del daño moral pertenece al pasado y debe ser superada, como ya lo ha sido en el Derecho comparado. Hoy el daño extrapatrimonial protege más allá del pretium doloris que es solo una especie del mismo. Así, si la víctima ha sufrido un daño corporal o un daño a la dignidad humana, a la libertad o a otros derechos de la personalidad, debe ser indemnizada por daño moral. Se resarce el daño no patrimonial incluso de aquellas personas allegadas a la víctima de un accidente mortal o una lesión muy grave.
\end{abstract}

Palabras clave: Pretium doloris; daño moral; daño extrapatrimonial.

ABSTRACT: Considering the scope of its protection the violation of an interest may justify compensation of non-pecuniary damage. Not only the pain and suffering must be compensated into this concept. This is an old point of view that reduces the compensation of non pecuniary loss to "pretium doloris" and it was left behind, a long time ago, in the comparative law. Today, who has suffered has suffered personal injury; or injury to human dignity, liberty, or other personality rights, must be compensated for non pecuniary loss or damage too. It could also be the subject of compensation for persons having a close relationship with a victim suffering a fatal or very serious non-fatal injury.

Key words: Pretium doloris; non pecuniary damage; non pecuniary loss.

\section{INTRODUCCIÓN}

La nomenclatura "daño moral" no es la que mejor identifica el conocimiento, contenido e indemnización del perjuicio extrapatrimonial, al que por cierto preferimos denominar de esta forma, más de acuerdo a la moderna doctrina existente en el Derecho comparado.

No hay una clara diferencia entre los conceptos que se indemnizan dentro del "daño moral". Se hacen presunciones en su prueba, que recurren a dar muchos supuestos por probados, bastando solo alegarlos. De las sentencias judiciales nunca se sabe si un daño extreapatrimonial produce insomnio genera depresión o viceversa, como tampoco si de ellos deriva intranquilidad solamente o zozobra y angustia. No se precisan sus consecuencias o si son situaciones aisladas. ¿Son todos ellos daños psicológicos? Tampoco la mayoría de las sentencias lo aclaran, como escasas también resultan las que razonan

\footnotetext{
* Doctor con mención "Doctor Europeus" Universidad de Salamanca, España; Magíster en Derecho de Empresas, Pontificia Universidad Católica de Chile; Profesor de Derecho Civil de la Pontificia Universidad Católica de Chile.
} 
sobre la cantidad de dinero que se otorga por ellos, especialmente en nuestro país, lo que en caso alguno debe llevar a pensar que solo los tribunales son responsables de ello, sino que también los litigantes, quienes poco aportan en su diferenciación al momento de solicitar su indemnización o el rechazo de la misma ${ }^{1}$.

Creemos necesario aclarar algunas ideas sobre la evolución que ha tenido esta figura en el Derecho comparado con algunas referencias a derechos continentales y del Common Law y la importancia que para su comprensión tiene una justificación jurídica y dogmática de la realidad del dolor y del sufrimiento en el Derecho chileno, en el que entendemos urge una renovación, sobre todo en la jurisprudencia.

\section{DAÑO MORAL, UNA ACEPCIÓN CON INFLUENCIA CANÓNICA}

Pesa sobre el daño moral, y mucho todavía, el perjuicio patrimonial en todos sus aspectos. Desde los elementos que se toman en cuenta para su existencia y concurrencia en los casos particulares, hasta la forma y cuantía de la indemnización. Sin embargo, pesa más todavía la implicación valórica de denominar a un daño como "moral".

Los términos "daño moral", que designan este tipo de perjuicio extrapatrimonial en su acepción más extendida, tendrían su origen en una interpretación latina, y gracias a la influencia del Derecho canónico, de la institución del Derecho germánico antiguo "Wergeld" o "rescate de la sangre" o "dinero del dolor". Esta acepción, desde la cual nació el concepto moderno del Derecho alemán "Schmerzensgeld", también fue utilizada y aplicada en la península itálica, como asimismo en los antiguos territorios francos ${ }^{2}$.

Los autores del Código Civil francés, formados todos en la doctrina canonista, intentaron supeditar la "responsabilidad civil" a la "responsabilidad moral", lo que tuvo

\footnotetext{
${ }^{1}$ Solo a modo de ejemplo reproducimos en lo pertinente la petición de dos litigantes: "Que a fojas 495 el demandado Rolando Hernán Fuschlocher Vaccaro contestó la demanda solicitando su rechazo, con costas, pues los gastos de repatriación de las víctimas fueron soportados por la empresa Cascada Expediciones y los demás, debian ser probados; que en cuanto al lucro cesante, no produce indemnizar al querellante por las remuneraciones que recibia su cónynge ni menos que esta trabajaría hasta los 85 años de edad; y que para indemnizar el daño moral, mejor denominado pretium doloris, identificándolo con el sufrimiento físico y psíquico, extrapatrimonial, que se causa al perjudicado en la lesión, debe acreditarse el detrimento en alguno de los atributos de la personalidad. Vigésimo sexto: Que a fojas 534 el acusado Yerko Andrés Ivelic, Kehsler, por sí, y en representación de la empresa Cascada Limitada, contestó la demanda civil solicitando igualmente su rechazo, con costas, pues no tiene responsabilidad alguna en el cuasidelito que se investiga, agregando además que no se ha acreditado que el demandante civil viva a expensas de su cónyuge ni que no tenga medios para solventar su vida, y que en nuestro pais las indemnizaciones pretium doloris no superan los $\$ 20.000 .000$ y que la sociedad demandada no se encuentra en las hipótesis del artículo 2320 ni 2322 del Código Civil". Edward Young Harper con Rolando Hernán Fuchslocher Vaccaro; Yerko Andrés Ivelic Kehsler (2007). En fallo reciente la Corte de Apelaciones de Valdivia ha señalado: "UNDÉCIMO: Que la determinación del resarcimiento del daño moral, como equivalente al pretium doloris es una materia que queda entregada al libre arbitrio del Tribunal, buscando cumplir con la justicia e igualdad". Diego Errázuriz Koerner; Soledad Fernández Kaltwasser; Soledad Errázuriz Fernández; Andrea y Trinidad ambas Errázuriz Fernández; Bárbara Musalem Araos; José Miguel Musalem Sarquis; Maria Eugenia Aros Marfil; Juan Luis Montalva Brahm; Juan Pablo Montalba Brahm; Juan Pablo Montalba Rodriguez; Cecilia Brahm Maura con Fisco de Chile (2007).

2 SLABY et al. (1980) han traducido Wergeld como "rescate de la sangre". Sobre el tema vid. HofsteTtER (1961) p. 9; Le Goff (1969) p. 66; CANTÚ (1848) pp. 40-42.
} 
como consecuencia principal colocar a la "culpa" en el centro del sistema de la responsabilidad civil. La moral, al tener como fundamento las nociones del bien y del mal, requiere la reparación del dañado causado cuando medie culpa o dolo del responsable o autor del daño.

Fue de esta manera y “...por influjo del Derecho canónico, especialmente preocupado del daño moral, que el Derecho común reelabora por completo la teoría de las consecuencias perjudiciales de la prestación no cumplida. Se traza una nueva concepción del damnum y del interesse' ". Así, los principios jurídicos y morales en el ámbito de la responsabilidad civil, además de la culpa, llevan a examinar las necesidades y la situación personal de la víctima del daño. Se impone, por lo tanto, la indemnización de aquellos males provenientes de daños y que inciden en el fuero interno del individuo que los padece, los dommage moral, al haber una identificación entre responsabilidad moral y legal ${ }^{4}$.

La propia expresión "daño moral" es un concepto jurídico que no delimita concretamente un significado particular. Resalta más bien la heterogeneidad de multiplicidad de supuestos o hipótesis de daños, los que por otro lado tienen la característica de irse renovando constantemente 5 . En este sentido y como señala Barros: "Lo cierto es que el término 'daño moral' tiende a oscurecer la pregunta por el tipo de daños a que se hace referencia. En efecto, la idea de un daño 'moral' alude correctamente a la lesión de bienes como el honor y la privacidad, pero solo imperfectamente expresa otros daños no patrimoniales, como, por ejemplo, el dolor físico, la angustia psicológica o la pérdida de oportunidades para disfrutar de una buena vida's.

\footnotetext{
${ }^{3}$ Aguilar y Herrera (1994) p. 56. Sobre estas "nuevas concepciones" del interés y el daño en perspectiva histórica, vid. Llamas (1999) pp. 107 y ss.

${ }^{4}$ Díez-Picazo señala, en relación al Código de Napoleón y el reconocimiento del daño moral, que: "los términos del artículo 1.382, que menciona cualquier daño, son tan amplios que permiten tanto el daño material como el moral; la reparación pecuniaria imperfecta del perjuicio moral debe preferirse a la falta de toda reparación; en toda decisión judicial hay siempre algo de arbitrario, pero la dificultad de la apreciación no debe influir en la prosperabilidad de una demanda justa". DíEZ-PICAZO (1999) p. 95.

5 En orden a atribuir un contenido amplio al concepto de daño moral, Carmen Domínguez señala que "estamos con aquellos que conciben el daño moral del modo más amplio posible, incluyendo allí todo daño a la persona en si misma "física o psíquica", como todo atentado contra sus intereses extrapatrimoniales. Comprende pues el daño moral todo menoscabo del cuerpo humano, considerando como un valor en si y con independencia de sus alcances patrimoniales". Y agrega "En suma, el daño moral estará constituido por el menoscabo de un bien no patrimonial que irroga una lesión a un interés moral por una que se encontraba obligada a respetarlo". (DOMINGUEZ (2002) pp. 83 y 84). Díez Schwerter ha dicho que "el daño moral consiste en la lesión a los intereses extrapatrimoniales de la víctima", y que "adoptando este criterio es perfectamente posible reparar todas las categorías o especies de perjuicios morales". DíEZ (1998) p. 88.

6 BARRos (2006) p. 231. En el mismo sentido, MARKESInis et al. (2005); MONATERi (1998) pp. 477-489; COMANDÉ (1999). En España ha sido reconocido el concepto a nivel doctrinal, legislativo y jurisprudencial. Vid., entre otros, a DE ÁNGEL YÁGÜEZ (1993) p. 698; VICENTE (1994) pp. 323. También, Anexo Ley de responsabilidad civil y seguro en la circulación de vehículos a motor, introducido por la Disposición Adicional 8a de la Ley 30/1995, de 8 de noviembre, de ordenación y supervisión de los seguros Privados (BOE, num. 268, 9.11.1995) y ST Constitucional de España 181/2000, de 29 de junio de 2000, puede visitarse en www.tribunalconstitucional.es/JC2000.htm, fecha de consulta 20 de marzo de 2007; sobre su influencia en el ordenamiento español en relación al daño corporal vid. MARTín-CASALS et al. (2003a) pp. 245 y ss.
} 
En la actualidad para solucionar el problema de la denominación moral del daño se acepta por la doctrina en general la expresión "perjuicio no patrimonial" o "daño extrapatrimonial" que empieza a generalizarse e incluso imponerse sobre la denominación "daño moral"7. Así, en Italia se le denomina daño no patrimonial ${ }^{8}$. En el Derecho alemán es “der nicht Vermögesschaden”, de acuerdo a los $\$ \$ 253,847$ y 1300 del BGB que es una expresión más amplia, comprensiva de toda esta categoría de perjuicios que escapan de la esfera patrimonial y que arranca del Schmerzensgeld, literalmente "dinero del dolor". La denominación se adopta por la dificultad extrema de su singularización y que además genera valoración por el uso de la palabra "moral" .

Esta confusión habría llevado a una enorme dificultad en la definición del daño moral. Por ello, lo primero que se extrae de los intentos de huir de la expresión "moral" del daño, es un esfuerzo por desligarlo de los perjuicios patrimoniales. Esta premisa se hace hoy extensiva tanto a su indemnización como también a la determinación de su quantum, especialmente en lo que a daños corporales se refiere ${ }^{10}$.

Los perjuicios patrimoniales se producen desligados de los morales y viceversa. Aunque pueden ser originados por un mismo hecho, son absoluta y totalmente autónomos. El juez no puede en su sentencia razonar el monto de la indemnización del daño moral en función de la que conceda por el perjuicio patrimonial o por la gravedad del ilícito cometido, como tampoco puede no dar lugar al resarcimiento del daño moral en razón de haber otorgado la indemnización por los perjuicios patrimoniales habidos ${ }^{11}$.

Como ejemplo de lo citado podemos referir en España la indemnización del daño moral para los casos de la ley de propiedad industrial, específicamente en el derivado de la lesión del derecho de autor, que se encuentra expresamente prevista por el art. 140 II Ley

\footnotetext{
7 ROGERS (2001) pp. 246; VON BAR (2000) p. 20.

8 Solo en Italia se reconocen tres formas de daños a las personas: el económico, el biológico y el no económico o moral, en el que las condenas no pasan de ser meramente simbólicas en la práctica. VON BAR (2000) p.181.

${ }^{9}$ En relación con el término alemán Schmerzensgeld, vid. VAN GerVen et al. (2000) p. 79, donde los autores señalan que en el Derecho comparado el concepto más parecido es el de la indemnización por "pain and suffering", y destacan que en el Derecho alemán es la reparación por todo el perjuicio no material o "Nichtvermögensschaden". Para una evolución histórica del Schmerzensgeld y el Derecho europeo en la materia hasta nuestros días vid. BARRIENTOS (2007).

${ }^{10}$ BARROS (2006) p. 325.

${ }^{11}$ No parece correcto el siguiente criterio de un reciente fallo de nuestro máximo tribunal, que reproduciremos en su parte pertinente más adelante, ya que expresa como parámetro de indemnización hechos completamente desligados del daño mismo que es la fuente y el origen de toda indemnización de perjuicios. Quien causa un daño a otro estará obligado a repararlo cuando no concurra una razón suficiente que justifique que sea el perjudicado quien haya de soportarlo, en otras palabras, si hay daño siempre debe haber indemnización, no existen otros parámetros que sí pueden concurrir en materia de delitos penales. Una es la responsabilidad civil, que es de la que hablamos cuando nos referimos al daño extrapatrimonial y otra muy distinta es la penal. La razón es muy simple, el daño puede ser un elemento del tipo penal o no, el daño siempre estará presente si de responsabilidad civil se trata y es el motivo de la indemnización civil. El fallo señala: "En este contexto, teniendo presente el sentimiento de afección o pretium doloris, se accederá al aumento del monto de la indemnización, tomando como parámetro no solo la naturaleza del hecho ilícito y del derecho agraviado, sino también las facultades económicas de sus autores". Igor Pérez Veloso; Silvia Jiménez Cid con Jaime Fernando Ruiz Paz; Juan Carlos González Cabezas; Giancarlo Canata Motto; Gerhard Walter Grebe; Miguel Edmundo Eulufi Cerda; Alexandra Fierro Araya; Inmobiliaria Paracadute Limitada (2006).
} 
de Propiedad Intelectual (LPI), que señala: "en caso de daño moral procederá su indemnización, aun no probada la existencia de perjuicio económico. Para su valoración se atenderá a las circunstancias de la infracción, gravedad de la lesión y grado de difusión de la obra"12.

Como crítica a la concepción del pretium doloris podemos señalar que en la práctica el daño moral se produce por el atentado a determinados derechos, bienes o intereses que el Derecho asegura a la persona. Ante la sola presencia de sufrimientos físicos o psíquicos no coexiste deber de reparación si no se consigue probar en juicio ${ }^{13}$. La prueba, además, debe encaminarse a determinar que se originan en un detrimento a cualquier bien jurídico tutelado.

Esfuerzos significativos en esta línea se pueden constatar en Europa en el caso de las lesiones corporales y el daño moral consecuencia de ellos, tal y como señalábamos. Pese a que hay una inmensa diversidad en las cuantías otorgadas por los tribunales en esta materia, podemos afirmar que los supuestos que cubre el daño extrapatrimonial hoy en el viejo continente van desde el daño a la integridad física, al perjuicio psíquico, la aflicción, la ansiedad, el temor, la angustia, la pérdida de agrado, etc. ${ }^{14}$.

No es entonces de extrañar que, en una primera contraposición con los daños que afectan al patrimonio, algunos autores hablen del daño moral como aquel que afecta a los sentimientos de las personas ${ }^{15}$. Sin embargo, como apunta Martín-Casals, "su alcance parece más amplio, como demuestra la progresiva consolidación en los ordenamientos europeos del daño biológico, que tiene una autonomía propia y reune unas características especificas, más allá de las consecuencias que pueda tener sobre los sentimientos de la persona"16.

\footnotetext{
${ }^{12}$ La mayoría de la doctrina española en el tema, considera que se debe circunscribir la apreciación del daño moral solo a la lesión de alguna de las facultades que integran el derecho moral de autor, de acuerdo al artículo 14 de la Ley de Propiedad Industrial. En este sentido: DíeZ-PICAZO (1989) p. 1698 y MARTíneZ (1996). En contra de la interpretación señalada: RODRíGUEZ y BONDía (1997), comentario artículo 135, p. 516; GARCÍA (2003) p. 651, quien señala que la lesión de valores inmateriales, entre los que por supuesto se cuenta el prestigio de la marca, no produce necesariamente daños morales, por lo que es preciso y pertinente distinguir la naturaleza de los daños de las dificultades probatorias respecto a la realidad y, más que nada, el gran problema que representa su cuantificación. En tribunales se pueden encontrar precedentes que interpretan los citados preceptos de manera más extensa e indemnizan el daño moral hasta "el sufrimiento y lesión en la sensibilidad artística" del autor que ve disminuida la integridad de su obra. STS de 3 de junio de 1991, RJ 1991, 4407. Para otros el Tribunal Supremo español lo que hace es apreciar un daño moral en todo tipo de incumplimiento de un contrato de explotación de una obra. CARRASCO (1993) pp. 1885 y ss.; sobre el tema vid. MARTín-CASALS (2003) pp. 245 y ss.; REGLERO (2003) pp. 1905 y ss.

13 CORRAL (2003) pp. 149 y ss.

14 Rogers (2001) pp. 268-279. En nuestro medio existen opiniones contrarias a esta división dentro de los perjuicios extrapatrimoniales ya que para Barros: "La extrema fragmentación del daño moral en incontables categorias y subcategorías tiene un alto grado de artificialidad, pues los bienes extrapatrimoniales no admiten divisiones demasiado nítidas. Así, una herida sufrida en un accidente puede dejar una cicatriz (perjuicio estético), que puede afectar la vida de relación (perjuicio de sociabilidad) y eventualmente generar dificultades para encontrar pareja (perjuicio sexual) y para formar una familia (perjuicio de afecto familiar), además de los sufrimientos físicos y el deterioro de la autoestima (pretium doloris). Se podrá comprender que estas categorías en gran medida se superponen, con la consecuencia de que una mecánica de fragmentación trae el riesgo de una doble o triple reparación de un mismo daño". BARROS (2006) p. 290.

15 ZWEIGERT y KÖTZ (1998); VON BAR (2000) p. 164.

${ }^{16}$ MARTín-CASALS et al. (2003b) p. 858.
} 


\section{EL PRETIUM DOLORIS ES UNA ESPECIE DE DAÑO EXTRAPATRIMONIAL}

Consideramos que la expresión "daño moral” se relaciona con un concepto jurídico indeterminado mucho más amplio hoy que el simple pretium doloris, que no es sino una especie más de daño moral. Esta expresión sería conveniente dejarla a un lado como expresión válida para este daño inmaterial. Existe una enorme heterogeneidad entre las hipótesis que hoy se clasifican como formas de daño extrapatrimonial. No es aconsejable, en consecuencia, elaborar un sistema que los encierre a todos, ya que con el tiempo tal enumeración quedaría superada ${ }^{17}$.

Por lo tanto, no todo daño extrapatrimonial es pretium doloris, aunque todo pretium doloris sí es un daño extrapatrimonial, hay una relación más bien de género a especie.

Otro problema que agrava todo lo anterior, es que en la actualidad lo que se entiende como daño moral puede dejar de serlo mañana gracias a la vida social que puede llenar positivamente de contenido la noción en estudio. En un momento determinado se puede considerar grave el ataque a un bien determinado y en otro puede parecer sencillamente irrelevante ${ }^{18}$.

En Chile, sin embargo, esta diferenciación aparece solo escasamente en la jurisprudencia incluso hasta hoy. Una sentencia recoge explícitamente y hace sinónimos el daño moral con el pretium doloris. La sentencia señala: "Que el actor a raíz del accidente y luego de un largo peregrinar por diversos centros hospitalarios, debió ser internado en el Hospital del Trabajador y sometido a cirugía, sufrió la pérdida de su ojo izquierdo y presenta incapacidad laboral del treinta y siete coma cinco por ciento (37,5\%) lo que lleva a la conclusión lógica que el accidente le ha producido no solo un daño y dolor físico, sino secuelas anímicas que le dan

\footnotetext{
17 Sin embargo, consideramos incomprensible el criterio de algunos sentenciadores en orden a que estas distinciones serían más bien académicas, nos preguntamos el porqué de tal conclusión ya que en los fallos no se señala el porqué sería así: "140) Que en cuanto al daño moral, el actor ha desglosado este concepto en los siguientes rubros: \$5.000.000 por daño corporal, el que denomina también daño físico, \$5.000.000 como pretium doloris, $\$ 5.000 .000$ por daño estético y \$60.000.000 por concepto de daño moral propiamente tal. 150) Que, a este respecto, si bien es posible teóricamente hacer la distinción que se plantea en la demanda, no resulta ajustado a la materia de que se trata, en un juicio de carácter laboral, establecer dicha diferenciación, por lo que al igual que la sentencia de primer grado, resulta más propio englobar todo el daño moral en un solo concepto, y habida consideración del perjuicio sufrido por el actor, ya acreditado con las pruebas que rolan en autos y todo ello sin perjuicio de la patología preexistente que padecia el actor, lo cual permite concluir que no todos los efectos de sus dolencias cabe atribuirselos exclusivamente al accidente, corresponde fijar esta indemnización de manera prudencial, tomando en consideración los aspectos ya mencionados, otorgándose en definitiva por concepto de indemnización por daño moral a favor del actor la suma única y total de \$20.000.000". Julio Riquelme Parra; con Southern Shipmanagement Limitada; Compañia Southern Shipmanagement CO Panamá Sociedad Anónima; Southern Shipmanagement Chile Limitada (2006).

${ }^{18}$ En el caso de faltas contra personas, desfiguraciones, así como actos violentos contra mujeres, habrían sido castigados con mayores multas que lesiones simples. Hasta muy entrada la Alta Edad Media la multa se medía también por el estatus social del lesionado. La justicia medieval, feudal y soberana además había conseguido que una parte de la multa fuera destinada al jerarca judicial. Era el fredus, denominado dinero de paz. HofstetTer (1961) p. 8.; en el mismo sentido, ForChielli (1983) p. 108. Para una descripción de este auge en Chile vid. COURT (2003) p. 102.
} 
derecho a impetrar una indemnización por daño moral -el daño moral es el equivalente al "pretium doloris"- y cuyo monto, según jurisprudencia reiterada, queda al arbitrio del juez de la causa con arreglo a las normas de la lógica y al conocimiento que da la experiencia de una forma equitativa y prudencial y aun en el caso que no se haya pedido monto alguno"19.

Como señala Domínguez Águila, en relación con el concepto de daño moral en la jurisprudencia chilena: "En nuestra jurisprudencia se tiende, las más de las veces, a confundirle con el dolor, la aflicción, el pesar experimentado por la víctima, concepción reductora que atiende más bien al efecto que a la causa y que determina la imposibilidad de entenderlo en personas privadas de sensibilidad o conciencia y que ha conducido, además, a la relajación de exigencias probatorias para su comprobación"20. Así, el daño moral que por su naturaleza, de acuerdo a los fallos chilenos, no está sujeto a las normas ordinarias sobre la prueba en general dado su carácter estrictamente subjetivo, que además no se manifiesta por los sentidos exteriores sino que se percibe interiormente, queda constreñido de contenido como concepto indemnizable. Se cierra la puerta con esta noción limitada al reconocimiento de una caracterización del mismo en distintas categorías. No es de extrañar, entonces, que la jurisprudencia de nuestros tribunales haya escasamente trabajado las figuras del perjuicio de afecto, de amenidad, sexual u otras que sí podemos individualizar en los ordenamientos europeos y que forman parte del daño extrapatrimonial.

\section{EL DOLOR Y EL SUFRIMIENTO EN RELACIÓN AL DAÑO EXTRAPATRIMONIAL}

Para que concurra el daño moral, no es necesario que existan sufrimientos o padecimientos de carácter físico y ni siquiera moral en las personas. ¿Se sufre por un daño, un mal o una privación? ¿El dolor es una afección, una emoción, una pasión o un sentimiento? ¿La enfermedad es algo nocivo que causa dolor y daño o es un mal que se sufre?

Limitar solo al sufrimiento físico o psíquico de la persona que padece los daños de este tipo, no explica indemnizaciones que hoy y desde hace décadas se conceden en la jurisprudencia comparada, habitualmente cuando ha existido una violación a ciertos bienes como el honor o la intimidad personal o familiar ${ }^{21}$.

19 Victor Manuel Anfossi Inzunza con Servicios Generales del Sur Limitada (2003).

20 Domínguez (2005) p. 621.

21 Desde 1954, BGH 25.5.1954, BGHZ 13, pág. 334, 338, los tribunales alemanes reconocen la tutela de los derechos de la personalidad (Allgemeines Persönlichkeitsrecht) y admiten la posibilidad de indemnizar los daños derivados de la lesión de esos derechos. En 1958 esa posición fue acogida por el Tribunal Constitucional Alemán, que en la sentencia de 15 de enero de 1958 reconoció que "el contexto jurídico de los derechos fundamentales como normas objetivas afecta al derecho privado... el cual debe adaptarse a los valores personificados por los derechos fundamentales" (BverfGE 7, 198, pág. 205-206.). La jurisprudencia constitucional alemana reconocía asi la eficacia entre particulares de los derechos fundamentales, que en el caso del derecho de la personalidad se concretaba en su reconocimiento como uno de esos "otros derechos" protegidos por el \$ 823(1) BGB cuya lesión daba lugar al resarcimiento de los daños y perjuicios producidos. Con ello, se producía lo que algún autor ha denominado "el más importante cambio en el derecho de la responsabilidad civil desde la aprobación del BGB". LARENZ y CANARIS (1994) p. 491. También en Francia la indemnización de los daños morales derivados de la lesión de derechos fundamentales se lleva a cabo mediante la aplicación de la regla general de responsabilidad civil por culpa de los arts. 1382 y 1383 Code Civil. VineY y JOURDAIN (1998) pp. 28 y ss.; GALAND-CARVAL (2001) p. 102. 
Creemos que entender el daño moral como una mezcla de las consecuencias del daño y el daño en sí mismo representa una limitación del concepto indemnizable en los daños extrapatrimoniales. Esto es lo que se logra en la definición de pretium doloris. El dolor y el sufrimiento son las manifestaciones de la lesión en el espíritu o en el cuerpo, es una consecuencia, nunca ella misma. De esta manera, la influencia de los estados anímicos sobre las funciones orgánicas y cómo las tensiones de cierta intensidad, pueden suscitar perturbaciones funcionales, a saber, hipertensiones, taquicardias o problemas endocrinos o cutáneos, son una manifestación en sí misma y no una consecuencia necesaria del daño extrapatrimonial.

La jurisprudencia nacional siempre se ha inclinado por la tesis del pretium doloris, sobre todo en cuanto a los efectos de los daños corporales. Así, el dolor de las heridas y el tratamiento médico, la pérdida de los sentimientos de valía personal o en medio determinado y el impacto que esto acarrea para la persona que lo sufre, han sido indemnizados sin demasiadas disquisiciones sobre su otorgamiento ${ }^{22}$.

La tesis del pretium doloris cooperó con el reconocimiento del daño extrapatrimonial y en los tribunales de justicia fue de gran ayuda, esto no se discute. Pero, con todo, creemos que ha sido absolutamente sobrepasada en la actualidad dogmática y empíricamente, porque lo que se entiende por daño extrapatrimonial es y debe ser considerado de manera más amplia en nuestros días. Pretium doloris es solo un tipo de daño moral y responde acaso a una de las definiciones más clásicas de daño moral ${ }^{23}$.

\footnotetext{
22 Barros (2006) p. 321.

23 Sentencias de tribunales chilenos refieren esta situación: "En lo que se refiere al daño moral nuestra legislación como la jurisprudencia han seguido una de las tesis más clásicas como el "pretium dolores", que afecta a la integridad espiritual de una persona, el que es apreciado por el juez de acuerdo a los antecedentes del proceso y la equidad". Corte Suprema de Chile (2002) Rol No 1.634-01; otro criterio utilizado es el de la naturaleza de las lesiones sufridas por el ofendido, tiempo del mal y menor capacidad deambulatoria (Corte de Apelaciones de Santiago (1984)); "El daño moral, tal como sostiene la jurisprudencia, es de indole netamente subjetiva y su fundamento se encuentra en la propia naturaleza de la psicología afectiva del ser humano, de tal manera que puede decirse que ese daño se produce siempre que un hecho externo afecta la integridad física o moral del individuo ...". Corte de Apelaciones de Rancagua (2001) Rol 198.494. La Corte Suprema declaró inadmisible el recurso de casación en la forma el 20 de diciembre de 2001, Rol 4812-01; se recurre en otras al criterio de la cantidad del mal (Corte Suprema (1981)); "Daño moral consiste en el dolor psíquico, y aun físico en sufrimientos, en general, que se experimenta a raiz de un suceso determinado". Sentencia de la Corte Suprema (1979); Sentencia de la Corte de Apelaciones de Santiago (1982 y 1984), Sentencia de la Corte de Apelaciones de Pedro Aguirre Cerda (1984); la naturaleza del hecho culpable y del derecho agraviado es otro de los criterios para fijar indemnización por daño moral, así como también las facultades del autor, condiciones y situación personal del ofendido y la forma como ha sido afectado en sus actividades normales (Corte de Apelaciones de Santiago (1990)); "Que sobre la indemnización por el daño moral para compensar de alguna manera el dolor, sufrimiento físico, angustias y depresión que afectó y afecta al actor...". Rol No 2.016-02, Corte Suprema (2002); se está en otras sentencias al análisis y circunstancias del hecho y de la víctima (Corte de Apelaciones de Santiago (1951)); “Daño moral es el dolor, la aflicción, el pesar que causa en los sentimientos o afectos el hecho ilícito, ya sea en la víctima o en sus parientes más cercanos". Corte de Apelaciones de Santiago (1973); "La determinación del monto de la indemnización por el daño moral corresponde a los jueces del fondo, en atención al sufrimiento, dolor o molestia que el hecho ilícito ocasiona en la sensibilidad física o en los sentimientos o afectos de una persona, lo que constituye una apreciación subjetiva que queda entregada al criterio y discernimiento de aquellos, valoración que no acepta revisión por este tribunal, por la vía de la casación de fondo". Corte
} 
A pesar de los extremos expuestos, es indiscutible que los tribunales tienden todavía a seguir la tesis del pretium doloris. Lo hacen en el entendido de colocar límites a los daños extrapatrimoniales indemnizables. Señalan que una cosa es aquella partida indemnizatoria que procede del dolor físico que sufre quien lo alega y otra, distinta, es la que tiene su causa en el dolor psíquico o padecimiento, al que identifican con el daño moral en sentido estricto.

Así, si un daño corporal afecta solo como dolor físico, no debiera concurrir indemnización por daño extrapatrimonial, pero si este además genera un dolor psíquico, deberá ser considerado como un comportamiento que, imputable al demandado, genere un daño no patrimonial y por el que corresponderá en consecuencia resarcimiento ${ }^{24}$.

No debe causar extrañeza el hecho de que la doctrina del pretium doloris esté siendo paulatinamente abandonada en Europa. No es fácil de entender en muchas hipótesis y en especial si se repara en el hecho de que el daño extrapatrimonial solo se podría deducir como alegación de reparación por una persona natural y no una jurídica como ocurre en la actualidad ${ }^{25}$. Por ello, como hemos apuntado más arriba, hoy se prefiere discutir sobre el carácter patrimonial o no patrimonial del derecho lesionado o también llamado extrapatrimonial ${ }^{26}$.

No podía ser de otra manera ya que sentir, en cualquiera de sus formas y grados, es el modo como todo viviente conocido se relaciona con su medio. Ello devela un elemento constitutivo de todo lo biológico: su interna conexión con el medio en el que vive. La alteridad en el Derecho es un rasgo que acá también se presenta. El Derecho impone a un individuo un deber, y confiere a otro un derecho para exigir el cumplimiento del deber. La norma jurídica no es una regla de conducta para individuos aislados, es una regla de convivencia que vincula a los individuos entre sí. Recordemos que esa obligación genérica de no causar daño a otro, lo que los romanos llamaban alterum non laedere, es la que crea la obligación de indemnizar si se contraviene, no es el dolor o el sufrimiento el que obliga a resarcir.

\footnotetext{
Suprema (2003) Rol No 679-02; el modo en que se produjo el delito o cuasidelito y todas aquellas circunstancias que influyen en la intensidad del dolor o sufrimiento (Corte de Apelaciones de Santiago (1944); "El verdadero daño moral corresponde a la situación de angustia, desesperación y detrimento que ocasiona, en el aspecto psíquico, en una persona...". Corte Suprema (2002) Rol 4035-2001.

${ }^{24}$ MARTÍN-CASALS et al. (2003a) pp.269 y ss.

25 "el generoso (en cuanto a la frecuencia y facilidad, no tanto en cuanto al dinero concedido) empleo de la indemnización por daño moral por el Tribunal Supremo podía explicarse sustancialmente por el intento de obtener un doble propósito: de una parte, sancionar conductas consideradas reprensibles cuando el daño patrimonial es típicamente bajo; de otra, eludir los más estrictos controles de naturaleza probatoria en cuanto a la cuantía aplicables al daño patrimonial en situaciones en las que la superación de los mismos es típicamente dificil para el demandante de resarcimiento del daño. Ambas motivaciones, y en particular la segunda de ellas, están presentes en la sentencia que se comenta y permiten entender (que no justificar) el uso del daño moral a la empresa como daño indemnizable en este caso". GÓMEZ (2002).

${ }^{26}$ LAlou (1962) p. 95; Eliashberg (1989) p. 24; BrebBia (1967) p. 67.
} 


\section{5. ¿QUÉ SE INDEMNIZA EN UN DAÑO EXTRAPATRIMONIAL?}

Los estímulos, en los vivientes dotados de sensibilidad, no se agotan en sensaciones, sino que además afectan, producen afecciones que se padecen, tal como lo entendían los griegos al hablar de pathemata o pasiones (gr. $\pi \alpha \theta 0 \varsigma$ = pathos). Estas quedan moduladas según los rangos de adecuación, conformidad o conveniencia que los estímulos tienen de acuerdo con la formalidad o fisiología del viviente, vale decir, quedan modulados según conformidad o disconformidad, provocando afecciones de placer o dolor, como son, por ejemplo, la sensación de satisfacción o insatisfacción respecto del alimento ${ }^{27}$.

La concepción de daño moral como pretium doloris, al centrarse solo en las sensaciones, induce a errores y grandes confusiones en la práctica. Homologar dolor, pesar, molestia, zozobra, inquietud, entre otros, sufridos por una persona como consecuencia de la conducta ajena, es un error manifiesto. ¿Cuáles son los límites? Sin precisarlos se les asigna una indemnización, en un monto que tampoco presenta mayores motivaciones y que la mayoría de las veces se basa en presunciones.

Lo anterior equivale a que, en general, el dolor y el sufrimiento son vistos como la causa del daño o su origen. Esto no parece adecuado, porque lo que son en realidad es una consecuencia o efecto de la iniuria o lesión que se ha inferido a los derechos extrapatrimoniales de la persona.

Los problemas que se generan con esta concepción del daño moral, por su imprecisión, entre otros son, que duda cabe, la exigencia de toda clase de pretensiones desmedidas de los litigantes, puesto que a cualquier molestia o pesar se le atribuye el carácter de daño extrapatrimonial indemnizable. Pareciera como si no fuera inherente a la vida humana el sentir, a menudo, tales abatimientos o desagrados en grados tolerables. No se puede tener una vida siempre libre de tales contratiempos, anestesiada, y menos pretender que siempre se indemnicen ante cualquier inobservancia en materia de daños los imputables a un tercero.

Esto demuestra la insuficiencia de la concepción del pretium doloris basada en la idea pura y simple del dolor, pesar o molestia, y lo escasamente sólida que resulta como argumentación ante el Derecho para fundar la responsabilidad civil por daños extrapatrimoniales en ella y, en consecuencia, para instituirse en fuente de la obligación de resarcimiento.

La doctrina mayoritaria en Chile opina que debe distinguirse en el daño moral, el llamado "puro" o "meramente moral" del daño moral con consecuencias pecuniarias ${ }^{28}$, como sería aquel atentado a la integridad corporal que acarrea disminución de la capacidad de trabajo. "Daño moral es el que afecta los atributos o facultades morales o espirituales de la persona"29. Es decir, lo que hemos caracterizado como pretium doloris y que la

\footnotetext{
27 ARISTÓTELES, Analitica priora et posteriora, 70 b 10.

28 ALESSANDRI (1943) p. 224. “...nuestro Derecho positivo ha considerado susceptibles de reparación, tanto a los daños materiales como a los exclusivamente morales. Por consiguiente, ambas categorías de daños son resarcibles en materia delictual o cuasidelictual, y nuestros juristas, catedráticos y quienes han hecho estudios sobre la materia, están acordes con ello". TAPIA (2006) p. 229.

${ }^{29}$ RDJ, T. 39, sec. $1^{\text {a }}$, p. 203.
} 
mayoría de la doctrina aún hoy reconoce como la forma de entender la indemnización del daño moral en Chile ${ }^{30}$.

Reducir la indemnización al dolor no es correcto a nuestro entender porque el dolor es una afección, es la forma como es conmovida la persona por la disconformidad de un estímulo sentido, disconformidad o asintonía con la estructura anatomofisiológica de la misma. Se olvida por parte de los tribunales, al fallar sobre estas materias, que la pérdida de agrados es también una manifestación del menoscabo que supone un daño extrapatrimonial, no se queda todo en el sufrimiento y resulta lamentable seguir limitando el contenido de la indemnización del daño moral a la simple apreciación del dolor ${ }^{31}$.

En general y en una perspectiva histórica, la jurisprudencia influenciada por esta explicación señalada, ha caracterizado al daño moral como el sufrimiento que experimenta una persona por una herida, la muerte de una persona querida, una ofensa a su dignidad u honor, la destrucción de una cosa de afección, etc.; es el dolor, pesar, angustia y molestias síquicas que sufre una persona en sus sentimientos a consecuencia del hecho ilícito ${ }^{32}$; un hecho externo que afecta la integridad física o moral del individuo ${ }^{33}$.

30 COURT (2003) p.105.

31 BARROS (2006) p. 322.

32 RDJ, T. 57 , sec. $4^{\mathrm{a}}$, p. 229 , T. 60 , sec. $4^{\mathrm{a}}$, p. 447 y T. 70 , sec. $4^{\mathrm{a}}$, p. 68.

33 RDJ, T. 58, sec. $4^{\text {a }}$, p. 375 y otras definiciones o intentos de ellas, como las que citamos a continuación:

"El daño moral, tal como sostiene la jurisprudencia, es de indole netamente subjetiva y su fundamento se encuentra en la propia naturaleza de la psicología afectiva del ser humano, de tal manera que puede decirse que ese daño se produce siempre que un hecho externo afecta la integridad física o moral del individuo y, por lo tanto, la apreciación pecuniaria de este debe considerarse por entero entregada a la apreciación discrecional del Juez, pues dado su naturaleza es inconcuso que no puede ni requiere ser acreditada". (Corte de Apelaciones de Rancagua (2001), Rol 198.494. La Corte Suprema declaró inadmisible el recurso de casación en la forma el 20 de diciembre de 2001, Rol 4812-01); "El daño moral es también indemnizable dentro del incumplimiento de una obligación contractual cuando se produce por culpa del deudor, pues la ley positiva no hace ninguna distinción al respecto entre daño material y daño moral, tanto más cuanto que ambos tienen una misma causa, aunque efectos diferentes. El daño material es, en la especie, la pérdida de la integridad corporal de un individuo, que se traduce en la disminución de su capacidad de trabajo; el daño moral afecta a la psiquis, en una depresión, en un complejo, en una angustia constante y permanente que, como el primero, repercute en la actividad de trabajo $y$, por ende, en las facultades económicas de la persona afectada". Corte Suprema (1951) R.D.J., t. 48, sec. 1a, p. 252.; "La indemnización por el daño moral para compensar de alguna manera el dolor, sufrimiento físico, angustias y depresión que afectó y afecta al actor, por la invalidez y pérdida de su capacidad de trabajo, por el acortamiento de su extremidad inferior derecha, y severas limitaciones en la movilidad de sus muñecas y de una de sus rodillas, será estimada por estos sentenciadores en una suma superior a la fijada por el tribunal de primera instancia, a fin de procurar que su situación sea más soportable y digna, todo ello en la forma que se expresará en lo resolutivo del presente fallo, y cuyo pago debe ser efectuado por los demandados por haber actuado sin la debida diligencia y cuidado". Considerando 70 sentencia Corte de Apelaciones, Rol de la Corte Suprema 2016-2002, de 30/09/2002.; Las sentencias de la Corte de Apelaciones de Santiago 26 de mayo 1944, Rev. de Der. y Juris., t. 41, sec. 24, p. 41 y, de modo esencial, la de la misma Corte de 11 octubre 1984, Rev. de Der. y Juris., t. 81, sec. 2a, p. 121: "El daño moral es de indole netamente subjetiva y su fundamento se encuentra en la propia naturaleza afectiva del ser humano, de manera que puede afirmarse que tal daño se produce siempre por un hecho externo que afecta la integridad física o moral del individuo. Por lo tanto, la apreciación pecuniaria de ese daño debe considerarse por entero sometida a la estimación discrecional del juez, ya que dada su indole es inconcuso que no puede ni requiere ser acreditada". Alessandri considera en general que para todo perjuicio se debe considerar para el monto de la reparación, la extensión del daño y no de la gravedad hecho. "Los tribunales chilenos, más por razones de equidad que jurídicas, tienen muy en cuenta la culpabilidad del agente, y, según sea más o menos grave, aumentan o reducen 


\section{DAÑO Y DOLOR NO SON LO MISMO}

El dolor suele producirse por la acción de variados factores que provocan un daño o lesión imputable a otro. No obstante, daño y dolor no son lo mismo. Pues hay daños que no se sienten, como el deterioro que puede producir silenciosamente un cáncer o sustancias nocivas contaminantes en el medio ambiente.

El daño o deterioro ha de ser sentido para que produzca dolor. Y por lo mismo puede ser suspendido, cortando la conexión del daño con la recepción sensitiva, como sucede con la sedación en todas sus formas. Son estas las razones que han llevado a buscar la indemnización del daño moral o extrapatrimonial ${ }^{34}$.

Estimulación y sensación no son lo mismo que suscitación, sensibilidad no es igual a susceptibilidad. La susceptibilidad o capacidad de respuesta varía de acuerdo a la formalidad habitual o habitud específica de cada persona.

Difícil y ardua de probar es entonces esta forma de entender el daño moral porque el hombre no puede sentir dolor sin tener una sensación real, es decir, la afección del dolor no queda como mera afección o pasión, sino como afección real. La realidad del dolor afecta realmente mi realidad y esto es un sentimiento y no una mera pasión como lo entendía la filosofía tradicional. El dolor entonces se sufre.

No basta, en consecuencia, seguir definiendo al daño moral dentro de la noción de daños patrimoniales al distinguir entre daños directos e indirectos. Tampoco es correcto seguir aseverando que los daños indirectos son los daños morales ya que tienen una repercusión indirecta en el patrimonio de la persona afectada. Como tampoco, que quedan fuera de la indemnización los indirectos en materia contractual y extracontractual, ya que se estima que respecto de ellos falta el requisito de causalidad entre el hecho y el daño producido, es decir, carecen de relación con el hecho ilícito ${ }^{35}$.

Es precisamente por estas razones que históricamente se limitaba en extremo la indemnización del daño moral, porque solo procedía la indemnización cuando "la repercusión psíquica del hecho ilícito, aquel conjunto de dolores, ansias, sufrimientos, se manifiestan en la esfera del sentimiento"36. Baudry-Lacantinérie planteaba hace ya más de un siglo "la desconsideración que para la persona atacada es el resultado del ataque, los sufrimientos síquicos, los disgustos, las inquietudes, que son generalmente las consecuencias del hecho

la indemnización". ALESSANDRI (1943) pp. 545 y 546. En contraste con ello se pueden también ver sentencias en que los factores que deben considerarse para la determinación del monto de la indemnización por daño moral son la naturaleza y gravedad del suceso que causa el daño como las de la Corte de Apelaciones de Santiago en sentencias de 4 de septiembre 1991, Gaceta Jurídica No 135, p. 95 (C. $8^{\circ}$ p. 97) y p. 103 (C. 6º, p. 105). Además de las de Rev. de Der. y Juris., t. 21, sec. 1a, p. 1053, t. 22, sec. 1a , p. 912 y t. 31 , sec. $1^{\text {a }}$, p. 1 .

34 "Los daños morales son bienes inconmensurables en dinero, porque no existe mercado para la vida, la salud o el honor. Sin embargo, esta inconmensurabilidad no impide en el derecho moderno su compensación. Razones de justicia correctiva y de prevención hacen preferible reconocer una indemnización basada prudencialmente en criterios imprecisos, a dejar daños relevantes sin indemnización alguna". BARROS (2006) p. 288.

35 AbeliuK (1993) p. 208. Expone una superación de estas ideas COURT (2003) p. 105.

36 Colasso (1949) p. 211. 
perjudicial'37. Sin embargo, parece bueno ir dejando a estos autores atrás, porque en estos temas, y especialmente en el daño extrapatrimonial, han cambiado mucho las cosas en los últimos cincuenta años, y todo hace pensar que lo seguirá haciendo.

La jurisprudencia chilena ha tenido la oportunidad de recalcar que la palabra daño comprende el perjuicio, dolor o molestia que se cause, por lo cual, interpretando este vocablo en su sentido natural y obvio, debe entenderse que corresponde, además del perjuicio pecuniario, el de carácter inmaterial que se ocasione por acto ajeno. Sostiene que siendo el daño por esencia patrimonial y extrapatrimonial, del mismo modo el daño moral juega tanto en la responsabilidad extracontractual como en la contractual ${ }^{38}$.

Dolor y sufrimiento no son lo mismo según hemos expuesto antes. De hecho, pudiera haber sufrimiento sin dolor, como sucede cuando acompañamos el dolor de otro, como ocurre en la compasión. Pero no podemos compartir el dolor ajeno, el dolor se pierde en el que lo siente. La realidad de un dolor pudiera afectar de modos extraños; podría, por ejemplo, dar alegría, pese a la intensidad del dolor, como la alegría del parto. La realidad del dolor puede afectar de variadas maneras, produciendo temor, ira, esperanza, tristeza.

Que el hombre no pueda sentir dolor sin más, sino sufriendo, lleva a decir, y con mucha razón, que simplemente el dolor "se sufre"; aunque dolor y sufrimiento no sean lo mismo. No todos sufrimos igual por un mismo dolor (imaginando que ese dolor sea igual), porque no todos somos capaces de asumir igualmente la realidad, por ejemplo, a causa de la edad. Es este precisamente un elemento tomado en cuenta en el Common Law para la indemnización del non pecuniary loss. La extensión de la apreciación de los demandantes del monto de la indemnización del non pecuniary loss, es alterado por las variables que la víctima toma en consideración para justipreciar el sufrimiento experimentado. Este nivel de percepción del dolor es determinante en casos de estado vegetal o lesiones serias del cerebro. Kemp and Kemp colocan un ejemplo clarificador de este punto. En el caso "Fallon v. Beaumont" de sentencia de 16 de diciembre de 1993, un hombre sufrió quemaduras en un $65 \%$ de su cuerpo y murió 30 días después del accidente. La mitad de su convalecencia él estuvo consciente de la gravedad de su estado y el resto del tiempo permaneció sedado. Incluso, la noche en que sabía que moriría pidió un sacerdote. Se le indemnizó en $£ 10.000$ por daños de pain, suffering y loss of amenity por los 30 días de convalecencia entre el daño y el día de la muerte. Kemp and Kemp comparan esta cifra con los $£ 1.500$ que solo recibió la víctima en "Doleman $v$. Deakin”, fallado el 24 de enero de 1990 (CA), donde pese a concurrir similares daños y la víctima fallecer 6 semanas después del accidente, es decir, un tiempo mayor que el

\footnotetext{
37 BAUdRY-LaCANTINÉRIE (1915) p. 579.

${ }^{38}$ FUEYO (1990) p. 71. Para su controvertida opinión en Chile, se apoya en las Sentencias de la Corte de Apelaciones Pedro Aguirre Cerda, 26 de diciembre de 1983, Gaceta Jurídica 46, p. 94, y Corte de Apelaciones de Santiago de Chile de 26 de septiembre 1990, Rev. de Der. y Juris., t. 87, sec. 31, p. 167, incluso agrega esta sentencia de 1990 elementos al concepto en desarrollo "daño moral es la lesión o agravio, efectuado culpable o dolosamente, de un derecho subjetivo de carácter inmaterial o inherente a la persona, imputable a otra, sea natural o jurídica". Finalmente, el reconocimiento de sus tesis también puede encontrarse de manera explícita en el fallo rol número 1.368-00, de 05/11/2001, de la Corte Suprema.
} 
primer caso relatado, se indemnizó con menor monto porque la víctima permaneció inconsciente las 6 semanas de convalecencia ${ }^{39}$.

\section{EL DINERO Y SU FUNCIÓN EN LA INDEMNIZACIÓN POR DAÑO EXTRAPATRIMONIAL}

La tradición filosófica ha dicho que el hombre se halla en la realidad intelectiva y volitivamente, inteligiendo, queriendo. Ha reservado la aisthesis o sensibilidad a una simple afección estimúlica carente de realidad. Por eso decía Aristóteles que la inteligencia permanece apathés o inafectada, no padece una afección, es impasible o, como solemos decir, funciona "fríamente". Sin embargo, el sentimiento es otra forma de estar en la realidad: "yo me siento" siempre de una u otra manera, aisthenomai $=\alpha \iota \sigma \theta \eta v o \mu \alpha \mathbf{l}^{40}$.

Es este el motivo por el que no es equivalente, en la indemnización del daño moral, el dinero con el daño sufrido, como asimismo, por principio es discutible, por no decir imposible, el daño extrapatrimonial de "ficciones jurídicas" como las personas jurídicas. El dinero no quiere ser una estimación en este caso de lo que se ha dañado. Simplemente quiere compensar, dando a la víctima una posible satisfacción que ponga a su alcance otros medios, otras satisfacciones que atenúen la pérdida sentida y que importan algo que el Derecho no puede desconocer nunca, cual es, que un bien extrapatrimonial que ha sido conculcado debe ser indemnizado.

La reparación por el dinero entonces solo cumple un rol como medida común de los bienes, pero no reemplaza la aflicción. Sustituye en el caso de los bienes materiales la obligación incumplida por medio de la indemnización, pero en los daños extrapatrimoniales esto no puede realizarse.

Del griego aisthesis se ha formado la palabra "estimación" para referirnos a esta otra forma de 'apreciar' o valorar la realidad. Percibir con la inteligencia o con los sentidos, comprendiendo, viendo, oyendo. Una de las manifestaciones de lo señalado es precisamente darse cuenta de la enfermedad. La realidad del dolor queda en mí con toda su fuerza y riqueza real. Ahora bien, la presencia de la realidad en sí misma es necesaria para que haya estimación. ¿Estimación de qué?, de la riqueza actual de las propiedades reales de una cosa, es decir, de lo "bueno" que hay en las cosas y que en tanto bueno "para mî" se convierte en "valioso".

En una interpretación más moderna de lo expresado más arriba, Goodin distinguió entre: a) la compensación que reemplaza los medios, means replacing compensation, que da medios equivalentes para la obtención de similares fines, es decir, busca proporcionar al dañado medios equivalentes para alcanzar los mismos fines; b) la compensación que desplaza los fines, ends displacing compensation, que no coopera a perseguir los mismos fines de otra forma, sino que más bien intenta dejar a la víctima en la misma

\footnotetext{
39 KEMP \& KEMP (2003). En relación a los elementos tomados en cuenta en la indemnización de daños extrapatrimoniales en el sistema ingles, recordemos que en el Common Law se consideran elementos como gravedad, nivel de percepción de la víctima del dolor, edad y estado civil de la víctima, reducción de la esperanza de vida y hasta el género, entre otros, para indemnizar los non pecuniary loss. BARRIENTOS (2007) pp. 426 y ss. ${ }^{40}$ Aristóteles, Metafísica, Libro I $\alpha 980$ a 24.
} 
situación que se encontraba antes del daño. Busca, por lo tanto, dar satisfacciones equivalentes a través de distintos fines ${ }^{41}$.

Martín-Casals opina que la única posible en materia de daños morales es la ends displacing compensation. En esta la víctima busca ser puesto en una situación ex ante pero de manera diferente ${ }^{42}$.

Para que la indemnización en dinero pueda otorgarse por equivalencia, debe siempre estar en presencia de situaciones que al menos sean homologables al dinero, cantidades homogéneas que por otro lado puedan compararse. En los daños morales esto no ocurre. El dinero jamás podrá reemplazar una pérdida tan grande como un padre a un menor de edad, sencillamente porque un padre a esa edad es irreemplazable ${ }^{43}$.

Lo que el dinero puede hacer, y en realidad es su única función en la indemnización por daños morales, "es ofrecer unos bienes de diferentes características, que respondan a unos deseos totalmente diferentes y que proporcionen diferentes satisfacciones. Debe servir de medio para posibilitar al dañado perseguir otros fines que le dejen en una situación que, aunque sea diferente de la existente ex ante, sea tan favorable como aquella"44.

Resulta difícil representarse que el dinero pueda servir para el restablecimiento de bienes que son personalísimos ${ }^{45}$.

No puede, entonces, pensarse que el dinero tiene el mismo fin en la indemnización del daño patrimonial y el extrapatrimonial. No es así. Lo bueno es una realidad de sentido en la que las cosas adquieren la condición irreal de buenas para mí (irreal es una forma de realidad y no mera "no realidad"). En cambio lo malo, como disconformidad, ha sido tratado desde San Agustín como una privación del bien conforme al bien del hombre. Privación no es mera carencia, sino carencia de lo que se debe tener ${ }^{46}$.

\section{8. ¿HACIA DÓNDE DEBE IR LA INDEMNIZACIÓN DEL DAÑO EXTRAPATRIMONIAL?}

La indemnización patrimonial por daños extrapatrimoniales debe hacer posible la satisfacción de intereses y aspiraciones personales. Se debe buscar compensar el daño no

\footnotetext{
41 GOODIN (1989) p. 60.

42 Martín-CASALS (1990) pp. 1231 y ss.

43 "la indemnización no hace desaparecer el daño, ni tampoco lo compensa en términos de poner a la víctima en una situación equivalente a la que tenía antes de producirse aquel (...), la indemnización por daño moral está dirigida a dar, a quien ha sufrido el daño, una satisfacción de reemplazo" (Corte de Apelaciones de Santiago, 18.11.2002, GJ 269, 90); que "aunque la pérdida sufrida por los padres de una niña de cuatro años violada y asesinada es irreparable y la vida que se quitó no puede ser avaluada en dinero, debe fijarse, prudencialmente, una suma por el rubro objeto de la demanda" (Corte de Apelaciones de Talca, 3.6.2000, 19.12.2000, GJ 246, 122, publicada también en F. del M. 505, 4813). BARros (2006) pp. 217.

44 MARTÍN-CASALS (1990) pp. 1238 y ss.

45 Como señala el profesor Llamas: “...la indemnización rara vez alcanza a 'eliminar' el daño, sino que más bien tiende a 'reparar' el mismo, y segundo, porque el interés que satisface la ejecución forzosa no es propiamente la prevención de un daño, sino el interés positivo que tiene depositado el acreedor en el cumplimiento de la obligación; no se trata ya de 'evitar el daño' como de 'conseguir la prestación'”. LLAMAS (1999) pp. 235.

46 “...nadie es malo por naturaleza, pero quien sea malo es por la perversión de la naturaleza”. SAN AGUSTíN, Ciudad de Dios, XIV, 6.
} 
patrimonial producido, porque si bien se ha causado una pérdida irreparable, se debe colocar a la víctima en una situación patrimonial mejorada, que posibilite, por lo tanto, mayores satisfacciones que de alguna manera compensen las sensaciones desagradables sufridas.

La indemnización por daño moral en este punto se realiza de acuerdo con los daños que se deben compensar. Se toma en cuenta: el alcance de los daños, así como su intensidad; la duración de los dolores, sufrimientos y los perjuicios ${ }^{47}$.

Sin duda, el mal es privación de un bien, pero el bien no es privación de un mal. El mal presupone el bien, pero el bien no presupone el mal, como enseñaba Santo Tomás de Aquino. El mal no es una cosa, sino un defecto privativo en la condición de buena de las cosas y que impide mi plena realización. La salud es ciertamente una ausencia de enfermedad, su integridad no es imaginable sin el mínimo de salud mental que se requiere para saberse sano y soportar en ese estado el mayor espacio de tiempo en aras de lograr bienestar. La llamada salud básica es la ausencia de mal o menoscabo análogo y no admite grados intermedios. La reserva de salud, por su parte, equivale a ese conjunto de bienes sicofísicos que permiten resistir el asedio de la enfermedad y capacitan para enfrentar los avatares que una patología supone en la vida de cualquier persona, entre otros, la fatiga, la desilusión y la erosión o merma, incluso, de la voluntad de continuar con una existencia que se considera penosa.

No podemos entonces considerar a la salud como un estado absoluto de la persona. Desde el punto de vista fáctico de la vida misma, la salud no es sino ese estado corporal que permite integrar la ausencia de enfermedad y la aptitud para poder rechazar la enfermedad, un estado de equilibrio bastante precario, dicho sea de paso. Es, entonces, ese estado preferible de relación entre la persona y los medios que en el presente le hacen apreciar su existencia y, hacia el futuro, ordenan sus proyectos y esperanzas ${ }^{48}$.

¿Qué papel juega, entonces, el dinero como indemnización por daños extrapatrimoniales?

La aptitud del dinero para aportar satisfacción pareciera seguir una discutible línea: "a mayor patrimonio menores son las satisfacciones que puede proporcionar a su titular una misma suma pecuniaria." Sin embargo, hay que ser categórico en defender que el daño moral producido no es borrado por una suma de dinero que se entrega a título de indemnización. Eso no es posible, porque la indemnización se radica en el patrimonio y no influye sobre las angustias, zozobras o malestares, que pertenecen más bien al fuero

\footnotetext{
${ }^{47}$ Para Martín-Casals, es esta la tesis que se sigue en España, Francia e Italia. Alemania la habría abandonado a partir de 1955. MARTín-CASALS (1990) p. 1240.

${ }^{48}$ Hay, evidentemente para el Derecho, un interés en que ese equilibrio se mantenga. Especialmente, en la protección de aquellos bienes que pueden resultar dañados extrapatrimonialmente. Los países incorporan las soluciones de técnica jurídica que velen por la diligencia exigible en la actividad profesional de restauración de la salud. Renunciar a tal mandato constitucional, sería abandonar y traicionar al Derecho mismo. Es importante en este sentido cómo la apreciación en abstracto de la culpa civil profesional y la apreciación en concreto de la culpa penal de igual naturaleza, que tienen metodologías inductivas distintas, conocen, como género próximo, la realidad que sustenta la culpabilidad de un facultativo de la Medicina. Se valora en ambos casos la pericia o diligencia especializada de los especialistas de la Medicina, que no es otra cosa que la diligencia exigible en las actividades del profesional. Vid. ZorRILLA (2001) pp. 209-227.
} 
interno del individuo o víctima del perjuicio. El patrimonio no es un atributo de la personalidad que logre generar automáticamente sensaciones agradables compensatorias de daños morales. En el mejor de los casos generará libertad económica, pero la experiencia de vida que logre superar o al menos aprender a convivir con las secuelas de un daño moral, obedecen a un esfuerzo físico y psíquico del perjudicado.

De modo que la enfermedad, como un mal, no es un mero daño o deterioro, sino un menoscabo en la salud, como estatus plenario de la sustantividad humana y no de su persona (la plenitud personal es un asunto muy diferente, ese sí que es un asunto moral).

Es importante tener en cuenta esta distinción, porque a primera vista quien tiene el defecto físico de la cojera no hace cosas malas ni es malo por ello, sino que solo anda mal cuando camina. Si entendemos que el daño extrapatrimonial solo toma en cuenta este hecho, entonces es bastante claro que “...los daños y perjuicios acordados no reemplazan en el patrimonio de la víctima la desaparición de un elemento; engrosan el patrimonio ${ }^{\text {'49 }}$. Esta situación es especialmente sensible si las condiciones de la víctima son muy precarias, la suma de dinero puede llegar a una compensación excesiva, un verdadero enriquecimiento sin causa. Se violaría un principio que el Derecho civil chileno reconoce como un principio general que forma el Derecho privado en su conjunto ${ }^{50}$.

Todo lo expuesto supone una activa participación en la compensación de la víctima del daño. Es la víctima quien debe superar el daño moral sufrido, ya que a no dudarlo, la compensación en dinero es una indemnización que solo ayuda a superar el daño extrapatrimonial irrogado. No es el pago por una reacción subjetiva a un sentimiento desagradable ${ }^{51}$.

La cuantía de la indemnización del daño moral será el grado de dificultad objetiva de la superación del daño en relación a las características individuales de la persona víctima del daño bajo el criterio de un hombre medio. La predisposición del ofendido al dolor resulta del todo irrelevante. Es por ello que los criterios objetivos aparecen en la valoración del quantum indemnizatorio, pero ese es un tema que dejaremos para otra oportunidad.

Como crítica a la concepción del pretium doloris podemos señalar que en la práctica el daño moral se produce por el atentado a determinados derechos, bienes o intereses que el Derecho asegura a la persona. Ante la sola presencia de sufrimientos físicos o psíquicos no coexiste deber de reparación si no se consigue probar en juicio. Representa una limitación del concepto de daño moral entenderlo como una mezcla de las consecuencias del daño y el daño en sí mismo. Esto es lo que se logra en la definición de

${ }^{49}$ Ripert y BOUlanger (1956) p. 377.

${ }^{50}$ Así y solo por nombrar algunos artículos del Código Civil en distintas materias: en la accesión, artículos 658, 663, 668, 669; en las prestaciones mutuas 905 a 917; en la nulidad de los actos de un incapaz y nulidad de pago 1688 y 1578; en la lesión enorme en la compraventa 1889, 1990, 1893; en la acción de reembolso del comunero contra la comunidad 2307; en la restitución del pago de lo no debido 2295 y 2297; en el derecho de indemnización para los responsables civiles por hechos de terceros 2325. No es de extrañar que en Europa, el artículo 2041 del Código Civil italiano, los $\$ \$ 812$ a 822 del BGB alemán y los artículos 62 a 67 del Código suizo de las Obligaciones, hagan pensar más en una fuente de las obligaciones que en un principio general del Derecho privado.

${ }^{51}$ Köndgen (1976) pp. 118 y ss.; JÜlCH (1978) pp. 118 y ss. 
pretium doloris. El dolor y el sufrimiento son las manifestaciones de la lesión en el espíritu o en el cuerpo, es una consecuencia, nunca ella misma. La concepción de daño moral como pretium doloris, al centrarse solo en las sensaciones, induce a errores y grandes confusiones en la práctica. Homologar dolor, pesar, molestia, zozobra, inquietud, entre otros, sufridos por una persona como consecuencia de la conducta ajena, pareciera un error. ¿Cuáles son los límites? Sin precisarlos se les asigna una indemnización, en un monto que tampoco presenta mayores motivaciones y que la mayoría de las veces se basa en presunciones.

Lo anterior equivale a que, en general, el dolor y el sufrimiento son vistos como la causa del daño o su origen. Esto es un error, porque lo que son en realidad es una consecuencia o efecto de la iniuria o lesión que se ha inferido a los derechos extrapatrimoniales de la persona.

\section{CONCLUSIONES}

1. Reducir la indemnización por daño extrapatrimonial al dolor no es correcto, ya que el dolor es una afección, es la forma como es afectada la persona por la disconformidad o asintonía con la estructura anatomofisiológica de la misma. La pérdida de agrados o amenidades es también una manifestación del menoscabo que supone un daño extrapatrimonial.

2. El dinero que se paga como indemnización por daño moral no es una indemnización como la patrimonial. Simplemente quiere compensar, dando a la víctima una posible satisfacción que ponga a su alcance otros medios, otras satisfacciones que atenúen la pérdida sentida. La reparación en dinero únicamente cumple un rol como medida común de los bienes, no reemplaza la aflicción.

3. Para que la indemnización en dinero pueda otorgarse por equivalencia, debe siempre estar en presencia de situaciones que al menos sean homologables al dinero, cantidades homogéneas que por otro lado puedan compararse. En los daños morales esto no ocurre. El dinero jamás podrá reemplazar la pérdida de un ser querido, sencillamente porque esto es irreemplazable.

\section{BIBLIOGRAFÍA CITADA}

Abeliuk, René (1993): Las Obligaciones (Santiago, Editorial Jurídica de Chile) tomo I. Aguilar Ros, Paloma y Herrera Bravo, Ramón (1994): Derecho Romano y Derecho Canónico: Elementos formativos de las instituciones jurídicas europeas (Granada, Editorial Comares) $151 \mathrm{pp}$.

Alessandri, Arturo (1943): De la responsabilidad extracontractual en el Derecho Civil Chileno (Santiago, Imprenta Universitaria) 716 pp.

ARISTÓTELES: Analitica priora et posteriora.

ARISTÓTELES: Metafísica, Libro I $\alpha 980$ a 24.

BARRIENTOS ZAMORANO, Marcelo (2007): El resarcimiento por daño moral en España y Europa (Salamanca, Editorial Ratio-Legis) 573 pp. 
BARros, Enrique (2006): Tratado de Responsabilidad Extracontractual (Santiago, Editorial Jurídica de Chile) 1.230 pp.

BaUdry-LACANTINÉRIE, Gabriel (1915): Trattato teorico-practico di Diritto civile (Milano, T. IV).

Bondía, Fernando y RodrígueZ, José María (1997): Comentarios a la Ley de Propiedad Intelectual (Madrid, Civitas) 516 pp.

BrebBia, Roberto (1967): El daño moral (Rosario, Orbir).

CANTÚ, César (1848): Historia Universal (Traducc. A. FERRER, Madrid, Nueva Ed., vol. $\mathrm{XII})$.

CARRASCO, A. (1993): La jurisprudencia del Tribunal Supremo relativa a la responsabilidad contractual (España, Aranzadi Civil).

COlasso, Vittorio (1949): La responsabilità civiles del nuevo codice (Roma, Rist. dell'ed. T. II) $211 \mathrm{pp}$.

COMANDÉ, Giovanni (1999): Risarcirnento del danno alla persona e alternative istituzionali. Studio di diritto comparato (Torino, Giappichelli).

CORRal TALCIANI, Hernán (2003): Lecciones de responsabilidad civil extracontractual (Santiago, Editorial Jurídica de Chile) 423 pp.

Court, Eduardo (2003): "Daño Corporal y Daño Moral: Bases constitucionales de su reparación”, en: FERRADA, Juan Carlos (coord.), La constitucionalización del Derecho chileno (Santiago, Editorial Jurídica de Chile) 298 pp.

De Ángel YÁGÜEZ, Ricardo (1993): Tratado de Responsabilidad Civil (Madrid, Universidad de Deusto/Civitas).

DíeZ-PiCAZO, Luis (1989): Comentarios a la Ley de Propiedad Intelectual Madrid (Bercovitz, R. (coord), Madrid, Tecnos).

DíeZ-PiCAZO, Luis (1999): Derecho de daños (Madrid, Editorial Civitas) 367 pp.

DíEZ SCHWERTER, Luis (1998): El Daño Extracontractual. Jurisprudencia y Doctrina (Editorial Jurídica de Chile) 291 pp.

Domínguez ÁGuila, Ramón (2005): "Por la intransmisibilidad de la acción por daño moral", en: Estudios de Derecho Civil, Jornadas nacionales de Derecho Civil (Valdivia, Editorial LexisNexis) 774 pp.

Domínguez Hidalgo, Carmen (2002): El Daño Moral (Editorial Jurídica de Chile) Tomo I.

Eliashberg, Constant (1989): Responsabilité civile et assurances de responsabilité civile (Paris, L'argus de l'assurance) 366 pp.

ForChielli, Paolo (1983): Responsabilità Civile (Padova, Edit. Cedam Casa Editrice Dott. Antonio Milani).

FUEYO, Fernando (1990): Instituciones de Derecho Civil Moderno (Santiago, Editorial Jurídica de Chile) 578 pp.

Galand-Carval, Suzanne (2001): "Non-Pecuniary Loss Under French Law”, en: RoGERS, H., Damages for Non-Pecuniary Loss in a Comparative Perspective, (Wien /New York).

García, I. (2003): Comentarios a la Ley de Marcas (Navarra, Aranzadi) 651 pp. 
GÓmez POMAR, Fernando (2002): “Comentario a la sentencia del Tribunal Supremo, Sala 1a, 20.2.2002: el daño moral de las personas jurídicas”, en: In Dret, working paper No 105, octubre de 2002, disponible en: www.in-dret.com [fecha de consulta: 16 de marzo de 2007].

GoODIN, Robert (1989): "Theories of compensation”, Oxford Journal of Legal Studies, vol. IX N 1 (Spring): pp. 56-75.

Hofstetter, R. (1961): "Zur Geschichte des Schmerzensgeldes", Das Sachenrecht Pufendorfs, en: U 61.4763 HD jPlatz, J.

JÜLICH, H. (1978): Die Funktion des Schmerzensgeldes (Saarbrücken, Dissertation).

Kemp \& Kemp (2003): Personal Injury Law, Practice and Procedure (Peter Andrews QC, Raymond Machell QC, Martin Spencer QC, Muiris Lyons, Andrew Ritchie, Simon Levene (edit.), Inglaterra, Sweet \& Maxwell) 900 pp.

KÖNDGEN, W. (1976): Haftpflichfunktionen und Immaterialschaden am Beispiel von Schmerzensgeld bei Gefährdungshaftung (Berlin, Duncker und Humblot).

LALOU, Henri (1962): Traite pratique de la responsabilité civile (Paris, Librairie Dalloz).

LARENZ, Karl y CANARIS, Claus Wilhelm (1994): Lehrbuch des Schuldrecht II/2 (München, Beck) 491 pp.

Le Goff, Jacques (1969): La Civilización del Occidente Medieval (Traducc. J. de C. SERRA RÁFOLS, Barcelona, Juventud) 749 pp.

LlAMAS POMBO, Eugenio (1999): Cumplimiento por equivalente y resarcimiento del daño al acreedor (Madrid, Editorial Trivium) 334 pp.

Markesinis, Basil, Coester, Michael, Alpa, Guido y Ullstein, Augustus (2005): Compensation for Personal Injury in English, German and Italian Law (Cambridge, Inglaterra, Cambridge University Press) 260 pp.

MARTín-CASAlS, Miquel (1990): "Notas sobre la indemnización del daño moral en las acciones por difamación de la LO 1/1982”, en: asociación de profesores de derecho civil, Centenario del Código Civil (1889-1989) tomo II (Madrid, CEURA).

Martín-Casals, Miquel (2003): "Comentario a la Sentencia de 31 de Octubre de 2002”, Cuadernos Civitas de Jurisprudencia Civil, enero - abril: pp. 245-269.

Martín-Casals, Miquel, Ribot, Jordi y SolÉ, Josep (2003a): “Compensation for Personal Injury in Spain", Tort and Insurance Law, vol. IV, Bernard Koch y Helmut Koziol (eds. Coord.), editado por el "European Center of Tort and Insurance Law" (Austria, Springer-Verlag/Wien).

Martín-Casals, Miquel, Ribot, Jordi y Solé, Joseph (2003b): "El daño moral”, en: CÁmara, Sergio (coord.), Derecho Privado europeo (Madrid, Cólex) pp. 857-881

MARTínez Espín, Pascual (1996): El daño moral contractual en la Ley de propiedad intelectual (Madrid, Tecnos) 197 pp.

MONATERI, Pier Giuseppe (1998): "La responsabilità civile”, en: SACCO, Rodolfo. (dir. coord.), Trattato di Diritto Civile (Torino, UTET).

REGLERO, Fernando (2003): "Responsabilidad civil por daños a la propiedad industrial", en: Reglero, Fernando (coord.), Tratado de Responsabilidad Civil (Aranzadi) pp.1905 y ss.

Ripert, Georges y Boulanger, Jean (1956): Tratado de Derecho Civil (Traducc. Delia García Daireaux, Buenos Aires) tomo II. 
Rogers, Horton (2001): Damages for Non-Pecuniary Loss in a Comparative Perspective (Wien/New York).

SAN Agustín, Ciudad de Dios.

Slaby, Rudolf, Grossmann, Rudolf e Illig, Carlos (1980): Wörterbuch der spanischen und deutschen Sprache.

TAPIA, Orlando (2006): De la responsabilidad Civil en General y de la Responsabilidad Delictual entre los Contratantes (Santiago, LexisNexis) 654 pp.

VAn Gerven, Walter, LeVer, Jeremy y Larouche, Pierre (2000): Cases, Materials and Text on National, Supranational and International Tort Law (Oxford, Hart Publishing) $494 \mathrm{pp}$.

ViCENTE DOMINGO, Elena (1994): Los daños corporales: tipología y valoración (Barcelona, María José Bosch) 351 pp.

VIneY, Geneviève y JOURDAIN, Patrice (1998): "Les conditions de la responsabilité", en : GHESTIN, Jacques (dir.), Traité de Droit civil (Paris, LGDJ) 1374 pp.

VON BAR, Christian (2000): The Common European Law of Torts (Oxford, Clarendon Press) vol. II, 728 pp.

Zorrilla, Manuel María (2001): "Reciprocidad de la Medicina y el Derecho", Estudios de Deusto, vol. $49 \mathrm{~N}^{\circ} 2$ julio-diciembre: pp. 209-227.

ZweIGERT, Konrad y Kötz, Hein (1998): An Introduction to Comparative Law (Oxford, Clarendon Press) 358 pp.

\section{JURISPRUDENCIA CITADA}

Corte de Apelaciones de Santiago, 20 de mayo de 1944, Revista de Derecho y Jurisprudencia, tomo 41, sección $2^{a}$, p. 41.

Corte de Apelaciones de Santiago, 1 de junio de 1951, Revista de Derecho y Jurisprudencia, tomo 48, sección $4^{a}$, p. 74 .

Corte Suprema, 3 de julio de 1951, Revista de Derecho y Jurisprudencia, tomo 48, sección $1^{\mathrm{a}}$, p. 252.

Corte de Apelaciones de Santiago, 3 de junio de 1973, Revista de Derecho y Jurisprudencia, tomo 70, sección $4^{\mathrm{a}}$, pp. 65 y 67.

Corte Suprema, 19 de octubre de 1979, Revista de Derecho y Jurisprudencia, tomo 76, sección $4^{\mathrm{a}}$, p. 444.

Corte Suprema, 12 de agosto de 1981, Revista de Derecho y Jurisprudencia, tomo 78, sección $4^{\mathrm{a}}$, p. 120.

Corte de Apelaciones de Santiago, 13 de julio de 1982, Revista de Derecho y Jurisprudencia, tomo 79, sección 41, p. 125.

Corte de Apelaciones Pedro Aguirre Cerda, 26 de diciembre de 1983, Gaceta Jurídica 46, p. 94.

Corte de Apelaciones de Pedro Aguirre Cerda, 11 de julio de 1984, Revista de Derecho y Jurisprudencia, tomo 81, p. 175.

Corte de Apelaciones de Santiago, 16 de agosto de 1984, Revista de Derecho y Jurisprudencia, tomo 81, sección 41, p. 141. 
Corte de Apelaciones de Santiago, 11 octubre de 1984, Revista de Derecho y Jurisprudencia, tomo 81, sección 2a, p. 121.

Corte de Apelaciones de Santiago, 26 de septiembre de 1990, Revista de Derecho y Jurisprudencia, tomo 87, sección $3^{\text {a }}$, p. 167.

Corte de Apelaciones de Santiago, 4 de septiembre de 1991, Gaceta Jurídica No 135, p. 95 (C. $8^{\circ}$ p. 97 ) y p. 103 (C. $6^{\circ}$, p. 105 ).

Corte de Apelaciones de Rancagua, 8 de noviembre de 2001, Rol 198.494.

Corte Suprema, 20 de diciembre de 2001 (recurso de casación en la forma), Rol 4812-01.

Corte Suprema, 26 de marzo de 2002, Rol No 1.634-01.

Corte Suprema, 3 de septiembre de 2002, Rol 4035-2001. Disponible en: www.lexisnexis.cl [fecha de consulta: 30 de marzo de 2007].

Corte Suprema, 7 de enero de 2003, Rol No 679-02.

Victor Manuel Anfossi Inzunza con Servicios Generales del Sur Limitada (2003): Corte Suprema, 5 de junio de 2003, Rol No 1.842-03, número identificador LexisNexis: 26503, disponible en: www.lexisnexis.cl [fecha de consulta: 21 de marzo de 2007].

Julio Riquelme Parra con Southern Shipmanagement Limitada; Compañia Southern Shipmanagement CO Panamá Sociedad Anónima; Southern Shipmanagement Chile Limitada (2006): Corte Suprema, 4 de septiembre de 2006, Rol 3485-2006 (recurso de casación en la forma, rechazado, recurso de casación en el fondo, rechazado), número identificador LexisNexis: 35141, disponible en: www.lexisnexis.cl [fecha de consulta: 8 de enero de 2008].

Igor Pérez Veloso; Silvia Jiménez Cid con Jaime Fernando Ruiz Paz; Juan Carlos González Cabezas; Giancarlo Canata Motto; Gerhard Walter Grebe; Miguel Edmundo Eulufi Cerda; Alexandra Fierro Araya con Inmobiliaria Paracadute Limitada (2006): Corte Suprema, 28 de diciembre de 2006, Rol 3492-2005 (recurso de casación en el fondo, indemnización por cuasidelito de homicidio), número identificador LexisNexis: 35800, disponible en: www.lexisnexis.cl [fecha de consulta: 8 de enero de 2008].

Diego Errázuriz Koerner; Soledad Fernández Kaltwasser; Soledad Errázuriz Fernández; Andrea y Trinidad ambas Errázuriz Fernández; Bárbara Musalem Araos; José Miguel Musalem Sarquis; María Eugenia Aros Marfil; Juan Luis Montalva Brahm; Juan Pablo Montalba Brahm; Juan Pablo Montalba Rodríguez; Cecilia Brahm Maura; con Fisco de Chile (2007): Corte de Apelaciones de Valdivia, 15 de enero de 2007, Rol 836-2006 (recurso de apelación, materia: falta de servicio, accidente de tránsito, falta de señalización), número identificador LexisNexis: 35750, disponible en: www.lexisnexis.cl [fecha de consulta: 8 de enero de 2008].

Edward Young Harper con Rolando Hernán Fuchslocher Vaccaro; Yerko Andrés Ivelic Kehsler (2007): Corte Suprema, 3 de octubre de 2007, Rol 4505-2007 (cuasidelito de homicidio, recurso de casación en el fondo, rechazado), número identificador LexisNexis: 37689, disponible en: www.lexisnexis.cl [fecha de consulta: 8 de enero de 2008]. 